\title{
Overview of role of radionuclides in scanning the brain in health and disease
}

Volume 6 Issue 4 - 2017

\section{Preface}

When GN Hounsfield announced the development of a revolutionary technique called Computerised Axial Tomography (CAT) Scan in 1972, it was thought that nuclear imaging will get relegated to the pages of history. Since then the world has witnessed the development of MRI, spiral CT, 3-D reconstruction etc. Though the role of nuclear imaging has decreased with the advent of these techniques, it still occupies a niche for itself which cannot be usurped. In this article radio-nuclide scans of the brain will be briefly reviewed.

\section{Isotopes and imaging}

Though radio-isotopes ${ }^{73} \mathrm{As}$ (Arsenic), ${ }^{197} \mathrm{Hg}$ and ${ }^{203} \mathrm{Hg}$ (Mercury) have been used for brain scanning, Technitium pertechnetate $\left({ }^{99 \mathrm{~m}} \mathrm{Tc}-\right.$ pertechnetate) is most commonly used. Following intravenous (IV) injection its gamma ray emissions are captured by a gamma camera. The scanned image may be seen on a digital screen or on a developed photographic plate, where increased or decreased gamma emissions correspond to areas of 'hot' or 'cold' spots, respectively. ${ }^{1,2}$

\section{Technitium scans and BBB}

${ }^{99 \mathrm{~m}} \mathrm{Tc}$ pertechnetate scan: The pertechnetate $\left({ }^{99 \mathrm{~m}} \mathrm{TcO}_{4}{ }^{-}\right)$ion in technetium $(\mathrm{Tc})$ pertechnetate binds to plasma proteins, quickly moves into the extra-cellular space and distributes itself like the chloride $\left(\mathrm{Cl}^{-}\right)$ion in various organs except the normal brain because of the blood brain barrier (BBB). Thus, negligible uptake of the isotope by the normal brain prevents its effective visualisation by isotope scan, unlike other organs. ${ }^{3}$

Lesions: Any pathological process can break down the BBB, allowing the ${ }^{99 \mathrm{~m}} \mathrm{TcO}_{4}$ - ion to localise in the area as a 'hot' spot (positive scan), contrasting with the low uptake in the normal areas of the brain with intact BBB (negative scan). The differences in uptake are accentuated on immediate and/or delayed scans.

Vascularity: The more vascular the lesion, the more consistent is its demonstration by radioisotope scan. Tumours, inflammatory masses, abscesses, infarction, intra- and extra-cerebral haemorrhage all give positive scans. The ${ }^{99} \mathrm{mcO}_{4}$ - ion localisation is not specific for any lesion but occurs in any lesion where disruption of the BBB and the vascularity of the lesion allows high lesion-to-brain distribution ratio.

${ }^{99 \mathrm{~m}} \mathrm{Tc}$ pentetate scan: Pentate is diethylene-triamino-penta-acetic (pentetic) acid (DTPA) complexed with $99 \mathrm{mTc}$ in a sterile sodium chloride $(\mathrm{NaCl})$ solution. Administered IV, it is used commonly in renal scans, but it is also used in brain and lung scanning (Table 1). Being lipophobic, it does not cross the blood brain barrier. Therefore it is more useful as a non-specific angiographic radionuclide in brain scans. $^{4}$

\section{Space-occupying lesions}

Certain space-occupying lesions (SOL) such as meningioma, acoustic tumour, malignant glioma and brain abscess appear particularly prominent in scan. Since this technique images the entire head as opposed to slices, accurate localisation of lesions with respect to external observable landmarks is possible. On the other hand, in contrast to CT or MRI scan, radio-nuclide scan provides very little anatomical detail. ${ }^{5}$

Positrocephalogram: This is a record produced by the emission of positrons by short-lived isotopes of Arsenic ( $\mathrm{AN}=33, \mathrm{AW}=74.922)$, administered to facilitate localisation of brain tumours (vide infra).

Table I Radio-isotopes in brain scan

\begin{tabular}{|c|c|}
\hline $\begin{array}{l}{ }^{99 m} \mathrm{TcO}_{4} \text { (pertechnetate) } \\
{ }^{99 \mathrm{~m} T c-D T P A} \text { (pentetate) }\end{array}$ & $\begin{array}{l}\text { All space occupying lesions (inflammatory, } \\
\text { neoplastic etc.) }\end{array}$ \\
\hline 99mTc-HMPAO & Lipophilic, brain-specific radionuclides for \\
\hline or ${ }^{99 \mathrm{~m} T c-E C D}$ & SPECT scan or brain death diagnosis \\
\hline $\begin{array}{l}{ }^{133} \mathrm{Xe} \text { (Xenon gas) } \\
{ }^{85} \mathrm{Kr} \text { (Krypton) }\end{array}$ & Perfusion scan (for cerebral blood flow) \\
\hline Radio-arsenic & Positrocephalography \\
\hline $\begin{array}{l}\text { Short-lived isotopes produced } \\
\text { on-site by cyclotron }\end{array}$ & PET scan \\
\hline $\begin{array}{l}\text { Gd (Gadolinium) stable } \\
\text { isotope }\end{array}$ & Paramagnetic contrast in MRI scan \\
\hline
\end{tabular}

\section{Vascular lesions}

They are divided into; (a) infarcts; (b) hematomas; and (c) arteriovenous malformations (AVM). The last is described under dynamic radio-nuclide angioscan (DRA). Some infarcts may be successfully imaged in their sub-acute stage (days to weeks) and they are often positive especially in the $2^{\text {nd }}$ or $3^{\text {rd }}$ week. Many hematomas are positive in the sub-acute stage (first week), remain positive for several weeks and then return to normal on radio-nuclide scan. They cannot be seen in the late stages (months or years). Thus serial brain scanning can help to differentiate tumours from vascular lesions. ${ }^{6,7}$ 
Dynamic radio-nuclide angioscan:This involves obtaining rapid (1-second interval) images shortly after an IV bolus injection of ${ }^{99 \mathrm{~m}} \mathrm{Tc}$. It depicts blood flow through the brain and is particularly useful in patients with AVM. In this condition, gamma camera viewing of the posterior of the head and neck shows; (a) early appearance of radioactivity over the lesion (typical of AVM) compared to rest of the brain; (b) higher peak density of gamma emission and; (c) delayed washout of radioactivity in the delayed images. This can be compared with static scan images to confirm the increased amount of tracer localised in the region of AVM.?

\section{Scans to assess function}

One major application of radio-nuclide scan which have not been supplanted by the newer imaging modalities is the study of dynamic physiological and metabolic events in the brain. CT scan provides accurate anatomical information but no physiological details. The special applications of radio-nuclide scan include the following.

Radio-nuclide cisternogram: After a radioisotope is injected into the ventriculo-subarachnoid space, sequential scans are taken to demonstrate the circulatory pattern of CSF and delineate abnormalities of flow. ${ }^{8}$

Radioencephalogra:This is a curve showing the passage of an injected tracer through the cerebral blood vessels, as revealed by an external scintillation counter. Placing the same over 2 sides of the skull provides a comparative index of the circulation in the two carotid systems. ${ }^{8}$

${ }^{133}$ Xenon perfusion scan: This measures the actual blood flow per unit volume of brain (i.e. perfusion of brain at the tissue level), which cannot be adequately demonstrated by angiography (which demonstrates only larger vessels). Following a short period of inhalation of ${ }^{133} \mathrm{Xenon}(\mathrm{Xe})$ gas it rapidly enters the brain. External scintillation counters record the rate at which the radioactivity leaves the brain, which is proportional to the blood flow per unit volume of brain in the field of the detector. This investigative (rather than diagnostic) tool demonstrates areas of global or focal cerebral ischemia. $^{9}$

${ }^{85}$ Krypton scan: Following intra-carotid injection of ${ }^{85} \mathrm{Kr}$ (Krypton) external scintillation counter records the rate at which radioactivity leaves brain, which is proportional to blood flow per unit weight of brain. Therefore, the principle is same as for ${ }^{133}$ Xenon perfusion scan. By these techniques it has been demonstrated that normal cerebral blood flow is $50-60 \mathrm{ml} 100 \mathrm{gm}^{-1} \mathrm{~min}^{-1}$.

Note, however, Positron Emission Tomogram (PET) scans (vide infra) or Functional Magnetic Resonance Imaging (fMRI) scan are more contemporary techniques that can be used to record regional brain activity. Any brain activity that causes increased blood flow to that region can be detected by these scans. For example, focusing on an object produces localized cerebral vasodilation and increased blood flow to the occipital lobe due to increased $\mathrm{O}_{2}$ usage and increased $\mathrm{CO}_{2}$ and $\mathrm{H}^{+}$production.

Positron scan: A positron (positive electron) $\left(\mathrm{e}^{+}\right)$is a positivelycharged anti-particle of electron possessing the same mass as the latter. It is emitted by radio-arsenic (q.v.) and other short-lived artificial radioisotopes which are produced on-site by a cyclotron. This scanning system (a.k.a. Positron Emission Tomography; PET scan), like the CT scanner, produces axial images of the brain, but unlike the latter, uses positron beam to do so. Moreover, by imaging the isotopes of carbon, nitrogen and oxygen in the molecules it enables visualisation of areas of metabolic dysfunction in the brain, in contrast to the anatomical information provided by the CT scanner.,
SPECT brain imaging:Single-photon emission computed tomography (SPECT) imaging is a functional nuclear imaging technique performed to evaluate cerebral perfusion. A 3-D image of cerebral blood flow can be demonstrated using a gamma camera. Cerebral perfusion is dependent on neuronal activity. A lipophilic, $\mathrm{Ph}-$ neutral brain-specific tracers like ${ }^{99 \mathrm{~m} T c-H M P A O}$ (hexamethyl-propylene-amine oxime) or ${ }^{99 \mathrm{~m}} \mathrm{Tc}-\mathrm{ECD}$ (ethylene cysteine diethylester) with a half-life of 6 hours is injected into the patient. This crosses the blood-brain barrier and emits gamma rays, which are captured by the gamma camera. The resultant image is reconstructed by the computer to generate a three-dimensional rendition of cerebral perfusion. ${ }^{3,10}$

\section{MR Spectroscopy}

Magnetic resonance (MR) spectroscopic analysis of ${ }^{31} \mathrm{P}$ (phosphorus) atoms allow non-invasive study of metabolic energy pathways of tissues. PET scan, MRI scan (infra) and MR spectroscopy are scanning techniques which involve imaging the nuclei of various atoms in tissues. ${ }^{8}$

\section{Gadolinium contrast in MRI scans}

Gadolinium $(\mathrm{Gd})$ is a rare element $(\mathrm{AN}=64, \mathrm{AW}=157.25)$ whose radioisotopes are frequently used in bone scans. In brain scan the stable element is used as gadopentate dimeglumine (dimeglumine salt of Gd complex of pentetic acid). Administered IV, it acts as a paramagnetic contrast agent* in MRI (Magnetic Resonance Imaging) of intra-cranial and spinal lesions. Magnetic resonance images the special magnetic properties of protons (nuclei of hydrogen atoms; $\mathrm{H}^{+}$) by subjecting them to electromagnetic radiation after placing them in a magnetic field. The nuclei absorb the energy and emit a radiofrequency signal which the scanner picks up as an induced current and gives a sectional image showing normal and pathological tissue with excellent contrast and detail. T1 images (which reflect the T1 property of protons) give good demonstration of normal anatomy, and T2 images (which reflect the T2 property of protons) are more sensitive to pathological changes. Both reflect the state of cellular and tissue water and fat, giving a discrimination of different tissue types. ${ }^{8,9}$

\{*Iron oxide is also used as a super-paramagnetic contrast agent in MRI of portal vein.?

\section{Brain death scans}

Radionuclide scans to assess brain death (or otherwise) involve usage of two distinct types of radiopharmaceuticals. The first, and the most preferred, are the lipophilic, Ph-neutral brain-specific tracers like ${ }^{99 \mathrm{~m}} \mathrm{Tc}-\mathrm{HMPAO}$ or ${ }^{99 \mathrm{~m}} \mathrm{Tc}-\mathrm{ECD}$ (q.v.). The second, and less preferred, is a non-specific lipophobic tracer like ${ }^{99 m}$ Tc-DTPA (q.v.), which is a vessel-specific angiographic radionuclide. In the flow phase, whether the tracer is brain-specific or angiographic, the tracer should be seen in the carotid arteries. This is essential to confirm that an adequate bolus was given. 15-20 minutes later (delayed phase), if the brainspecific tracer is seen in the brain substance and the angiographic tracer is seen in the dural venous sinuses, it indicates brain function is intact. In the delayed phase if the brain-specific tracer is absent in brain tissue or the angiographic tracer is not seen in the dural venous sinuses, it indicates lack of generalized cerebral perfusion, consistent with brain death. ${ }^{4,11,12}$

\section{Acknowledgments}

$$
\text { None. }
$$

\section{Conflicts of interest}

None. 


\section{Funding}

None.

\section{References}

1. Abdel-Dayem H Radionuclide Brain Scanning. Chapter 2020. p.1-30.

2. Nisbet AP, Ratcliffe GE, Ellam SV, et al. Clinical indications for optimal use of the radionuclide brain scan. Br J Radiol. 1983;56(666):377-381.

3. Vander Borght T, Laloux P, Maes A, et al. Guidelines for brain radionuclide imaging. Perfusion single photon computed tomography (SPECT) using Tc-99m radiopharmaceuticals and brain metabolism positron emission tomography (PET) using F-18 fluorodeoxyglucose. The Belgian Society for Nuclear Medicine. Acta Neurol Belg. 2001;101(4):196-209.

4. Patel R Tc-99m Brain Death (or Intracerebral Perfusion) Scan. Nuclear Medicine Resource.

5. Butler AR, Passalaqua AM, Berenstein A, et al. Contrast enhanced CT scan and radionuclide brain scan in supratentorial gliomas. Am J Roentgenol. 1979;132(4):607-611.
6. Bradač GB, Oberson R. Radionuclide Brain Scan in the Diagnosis of Cerebrovascular Diseases. Angiography in Cerebro-Arterial Occlusive Diseases. 1979. p.39-43.

7. Partain CL, Guinto FC, Scatliff JH, et al. Cerebral Venous Angioma: Correlation of Radionuclide Brain Scan, Transmission Computed Tomography, and Angiography - Case Reports. $J$ Nucl Med. 1979;20:1166-1169.

8. David C Jr, Sabiston MD. Davis-Christopher Textbook of Surgery. (12th edn), WB Saunders, USA. 1981; 10(3):202.

9. Snell, Richard S. Clinical Neuroanatomy for Medical Students. (7th edn), Wolters Kluwer/Lippincott, USA. 2010. p.1_878.

10. Tam M, Leung SSK, McCarthy M, et al. SPECT Brain Imaging. Drugs \& Diseases. 2015.

11. Zuckier LS, Kolano J. Radionuclide Studies in the Determination of Brain Death: Criteria, Concepts, and Controversies. Semin Nucl Med . 2018;38(4):262_273.

12. Sinha P, Conrad GR. Scintigraphic Confirmation of Brain Death. Semin Nucl Med. 2012;42(1):27 32. 